\title{
The role of CD18 in the production and release of neutrophils from the bone marrow
}

\author{
John C Gomez ${ }^{1,2,3}$ and Claire M Doerschuk ${ }^{1,2,3}$
}

Neutrophil numbers must be tightly controlled to maintain host protection and prevent neutrophil-mediated tissue injury. CD18 deficiency leads to neutrophilia and myeloid hyperplasia in the bone marrow (BM). These studies examined the function of $C D 18$ in regulating neutrophil production and determined whether the defects in neutrophil production that are observed in CD18 deficiency persist in the presence of wild-type (WT) leukocytes that confer host protection. Neutrophil production was evaluated in $\mathrm{CD}_{1} 8^{-/-}$mice and lethally irradiated WT mice reconstituted with mixtures of CD18 ${ }^{-1-}$ and WT stem cells. Neutrophil kinetic studies suggest that CD18 may facilitate the release of the most mature neutrophils into the circulation. The proportion of $\mathrm{CD} 18^{-1-}$ neutrophils in chimeric animals was greater than the proportion of $\mathrm{CD}_{1} 8^{-/-}$donor cells used to reconstitute the mice, and the percentage of $\mathrm{CD} 18^{-/-}$leukocytes that were neutrophils was greater than for WT leukocytes, indicating that CD18 may regulate the lineage distribution of hematopoietic cells in the blood and BM. The proportion of Annexin V $+\mathrm{Gr}-1+$ cells in both the BM of chimeric animals and in vitro cultures of WT and CD18 ${ }^{-/-}$hematopoietic stem cells was lower in $\mathrm{CD}_{18^{-/-}}$than in WT cells, suggesting that CD18 modulates apoptosis. These data suggest that CD18 directly regulates neutrophil production, in part by limiting the survival of neutrophils and their precursors. Thus, the granulocytosis observed in CD18 ${ }^{-1-}$ mice and CD18-deficient patients is due to both defects in host defense and BM-intrinsic functions of CD18 in regulating neutrophil production. Laboratory Investigation (2010) 90, 599-610; doi:10.1038/labinvest.2010.4; published online 8 February 2010

KEYWORDS: neutrophils; adhesion molecules; hematopoiesis

Integrins are noncovalently linked heterodimers of $\alpha$ and $\beta$ subunits that are expressed on the cell surface. ${ }^{1}$ The $\beta_{2}$ integrin (CD18) expressed on leukocytes can pair with several $\alpha$ integrin (CD11) subunits, and each $\alpha \beta$ pairing can bind a variety of ligands, including the counterreceptors ICAM-1, -2, and -3; fibrinogen; the complement fragment iC3b; and polysaccharides. ${ }^{2}$ Patients with heterogeneous mutations in the gene that encodes CD18 suffer from the clinical syndrome leukocyte adhesion deficiency type I (LAD I). LAD I is characterized by extremely high levels of circulating neutrophils, recurrent bacterial infections, impaired wound healing, and functional defects in neutrophils. Infected tissues from patients with LAD I generally lack extravasated neutrophils, indicating a functional requirement for CD18 in neutrophil migration into some tissues. These patients also exhibit myeloid hyperplasia in the bone marrow $(\mathrm{BM})$ and spleen. Mice have been generated that are com- pletely deficient in CD18, and their leukocytes express no functional leukocyte $\beta_{2}$ integrins, including LFA-1 (CD11a/ CD18 or $\alpha_{\mathrm{L}} \beta_{2}$ ) and Mac-1 (CD11b/CD18 or $\left.\alpha_{\mathrm{M}} \beta_{2}\right){ }^{3}$. The phenotype of these CD18 $8^{-l-}$ mice is similar to human LAD I patients, including granulocytosis, spontaneous infections, and myeloid hyperplasia. ${ }^{3}$ The granulocytosis in CD18 deficiency is present within the first few days of life, and occurs even when mice were housed in clean, specific pathogen-free facilities and in the absence of discernible infections.

Several mechanisms have been proposed to underlie the granulocytosis that occurs in CD18 deficiency. When lethally irradiated wild-type (WT) mice are given a 1:1 mixture of WT and CD $18^{-1-}$ fetal liver cells, granulocytosis is inhibited by greater than $95 \%$ compared with WT mice given $\mathrm{CD} 18^{-/-}$ stem cells alone, ${ }^{4}$ indicating that the granulocytosis seen in CD18 deficiency can be largely corrected by the presence of WT hematopoietic cells. These data led to the hypothesis that

\footnotetext{
'Division of Integrative Biology, Department of Pediatrics, Rainbow Babies and Children's Hospital and Case Western Reserve University, Cleveland, OH, USA and

${ }^{2}$ Department of Pathology, Case Western Reserve University, Cleveland, OH, USA

Correspondence: CM Doerschuk, MD, Department of Medicine, University of North Carolina at Chapel Hill, CB \#7248, 7011 Thurston-Bowles, Chapel Hill, NC 27599-7248, USA.

E-mail: cmd@med.unc.edu

${ }^{3}$ Current address: Department of Medicine, Center for Airways Disease, University of North Carolina, Chapel Hill, NC 27599, USA.

Received 28 July 2009; revised 17 November 2009; accepted 6 December 2009
} 
granulocytosis in CD18 deficiency is mainly due to the inability of mutant leukocytes to defend the host from microbial pathogens, resulting in chronic infection and subsequent chronic stimulation of the BM. The presence of WT neutrophils is thus postulated to remove the stimuli that increase neutrophil production in the $\mathrm{BM}$ by conferring protection to the host. ${ }^{4}$ Other studies have implicated a function for increased levels of circulating G-CSF and IL-17 in inducing neutrophilia. ${ }^{5,6}$ Forlow et al ${ }^{5}$ showed that $\mathrm{CD} 18^{-/-}$mice have increased levels of circulating IL-17 and G-CSF, and blocking IL-17 or G-CSF partially suppressed the neutrophilia in these mice. The inability of neutrophils deficient in CD18 or other adhesion molecules to migrate into tissues stimulates neutrophil production in the BM through increased levels of IL-23, IL-17, and G-CSF. ${ }^{6}$ Weinmann $e t ~ a l^{7}$ showed that circulating neutrophils in $\mathrm{CD} 18^{-I-}$ mice show decreased apoptosis, and the delay in apoptosis of CD18 $8^{-1-}$ neutrophils is abolished in the presence of WT leukocytes. Taken together, these studies indicate that CD18 regulates circulating neutrophil numbers through alterations in neutrophil production and turnover that can be largely corrected by the presence of WT leukocytes. These thus represent extrinsic defects that result from CD18 deficiency.

Intriguingly, a mild granulocytosis does develop in mice that received a mixture of $\mathrm{WT}$ and $\mathrm{CD} 18^{-1-}$ stem cells, ${ }^{4}$ indicating that cell-intrinsic mechanisms that cannot be corrected by the presence of WT cells also contribute to the granulocytosis observed in CD18 deficiency. In chimeric mice with both WT and $\mathrm{CD} 18^{-1-} \mathrm{BM}$, a larger than expected fraction of the circulating neutrophils are $\mathrm{CD} 18^{-/-}$and a much larger proportion of the $\mathrm{CD} 18^{-1-}$ circulating leukocytes are neutrophils, even in the presence of normal numbers of WT neutrophils in the blood and BM. ${ }^{4}$ These observations strongly suggest that $\mathrm{CD} 18$ can directly regulate neutrophil production in the BM through mechanisms that involve altering the lineage distribution of leukocytes. Thus, the mechanisms that underlie granulocytosis in CD18 deficiency are complex and may have important implications for understanding the regulation of neutrophil production in the BM.

Sufficient numbers of neutrophils are required to defend the host against pathogens, but excessive neutrophil accumulation and activation can cause tissue injury. The function of neutrophil-mediated tissue damage is well established in the pathogenesis of acute lung injury, ${ }^{8}$ ischemia-reperfusion injury, and other disorders. ${ }^{9}$ Consequently, the neutrophils in the circulation are tightly regulated. Understanding the mechanisms that regulate neutrophil production and release could lead to the development of ways to modulate these processes in ways to treat disease, either by enhancing production and release to promote the killing and removal of pathogens or by inhibiting release to prevent neutrophilmediated tissue damage.

Our present studies grew from our previous work showing that the granulocytosis observed in the absence of CD18 occurs through at least two mechanisms, one that is reactive and reversed by the presence of WT neutrophils and another that is not. ${ }^{4}$ These studies tested the hypothesis that CD18 has a direct and marrow-autonomous function in regulating neutrophil numbers by limiting the production of neutrophils from hematopoietic progenitors in the BM. Studies to examine neutrophil kinetics were undertaken in $\mathrm{CD} 18^{-1-}$ mice and in lethally irradiated WT mice reconstituted with a mixture of WT and $\mathrm{CD} 18^{-1-}$ stem cells. This approach allowed us to compare WT and $\mathrm{CD} 18^{-/-}$neutrophils that had been exposed to the same microenvironment and cytokine milieu within the host. In addition, proliferation and apoptosis were studied in cultured hematopoietic stem cells (HSCs) isolated from WT and $\mathrm{CD} 18^{-1-}$ mice. Our results show an increase in the commitment of $\mathrm{CD} 18^{-/-}$hematopoietic progenitors to the neutrophil lineage and a defect in apoptosis leading to decreased cell death. Thus, the data presented in this study suggest that CD18 has a direct function in the production of neutrophils in the BM by regulating the survival of neutrophils and their late-stage precursors, and by regulating the maintenance or proliferation of their more primitive precursors.

\section{MATERIALS AND METHODS \\ Mice}

C57BL/6 mice bearing the CD45.2 allele were obtained from Jackson Laboratory (Bar Harbor, ME, USA). In some studies, WT C57BL/6 mice bearing the CD45.1 allele were used as donors. Mice completely deficient in ICAM-1 or CD18 were generated as described ${ }^{3,10}$ and backcrossed to the C57BL/6 background. Leukocytes from mice deficient in CD18 express no functional CD11/CD18 integrins on their cell surface. All animals were maintained in a specific pathogen-free barrier facility and fed autoclaved food and water ad libitum. CD18 ${ }^{-1-}$ mice were given trimethoprim-sulfamethoxazole in their water. Animal studies were reviewed and approved by the Institutional Animal Care and Use Committee of Case Western Reserve University.

\section{Measurement of Circulating G-CSF Levels and Lung IL-17 mRNA}

Blood samples were obtained from age- and sex-matched $\mathrm{WT}, \mathrm{CD} 18^{-1-}$ and $\mathrm{ICAM}-1^{-1-}$ mice using a heparinized syringe. Plasma G-CSF levels were determined by ELISA (R\&D Systems, Minneapolis, MN, USA).

Total RNA was obtained from dissected lungs using TRIzol (Invitrogen, Carlsbad, CA, USA). RNA was reverse transcribed using oligo (dT) and random hexamer primers, and Superscript III reverse transcriptase (Invitrogen). The amount of specific message was quantitated using real-time quantitative PCR (ABI PRISM 7000 Sequence Detector Systems; Applied Biosystems, Foster City, CA, USA). Quantitative PCR was performed using SYBR Green PCR Master Mix (Applied Biosystems). The PCR was at $10 \mathrm{~min}$ at $95^{\circ} \mathrm{C}$, followed by $15 \mathrm{~s}$ at $95^{\circ} \mathrm{C}$ and $60 \mathrm{~s}$ at $60^{\circ} \mathrm{C}$ for 40 cycles. 
Fluorescence detection was reported at the end of each cycle. The quantity of message in each sample was correlated to the cycle at which fluorescence above baseline signal is first detected $\left(\mathrm{C}_{\mathrm{T}}\right)$. Each reaction was performed in triplicate, and the mean $\mathrm{C}_{\mathrm{T}}$ was determined. The amount of IL-17 mRNA was then normalized to the expression of mitochondrial $28 \mathrm{~S}$ ribosomal RNA in each sample. The primer sequences were as follows: IL-17 forward, 5'-GTTCCACGTCACCCTGGAC$3^{\prime}$; IL-17 reverse, 5'-CTTTCCCTCCGCATTGACAC-3'; $28 \mathrm{~S}$ mt rRNA forward, 5'-TGTGGATGGCGAGAAATACCA-3'; $28 \mathrm{~S}$ mt rRNA reverse, 5'-GCATCAGCCTCCAGTATAGTTGT-3'

\section{BM Reconstitution of Irradiated WT Recipients}

Livers from viable C57BL/6-CD45.1 and $\mathrm{CD} 18^{-1-}$ fetuses (13-14 days post-coitum) were excised and homogenized. Suspensions containing donor stem cells were prepared. To determine the fraction of fetal liver cells that could reconstitute recipients, we stained an aliquot of the fetal liver cell preparations for expression of lineage markers, c-kit and Sca-1, as described below for staining BM cells for HSC isolation and culture. Recipient C57BL/6-CD45.2 mice received 8 and 4 Gy radiation doses $3 \mathrm{~h}$ apart from a cesium137 source. Recipients were reconstituted by injection through the lateral tail vein of a $60: 40,1: 4$, or $4: 1$ mixture of WT C57BL/6-CD45.1 and CD18 ${ }^{-1-}$ fetal liver cells $\left(1-2 \times 10^{6}\right.$ per mouse). Animals were kept in a specific pathogen-free barrier facility and maintained on antibiotics for at least 4 weeks after reconstitution. Mice were studied at least 10 weeks after transplantation, several weeks after the time when committed myeloid progenitors from the fetal liver no longer contribute to myelopoiesis in the recipient. ${ }^{11}$

\section{Neutrophil Kinetics in CD18 ${ }^{-/-}$and Chimeric Mice}

Neutrophil kinetics was examined in $\mathrm{CD}_{1} 8^{-/-}$mice and in lethally irradiated WT mice reconstituted with a mixture of WT and $\mathrm{CD} 18^{-1-}$ stem cells. Chimeric animals were studied to exclude the confounding effects of the altered host environment and extreme neutrophilia on neutrophil kinetics in $\mathrm{CD} 18^{-1-}$ mice. This approach also allowed us to compare WT and $\mathrm{CD} 18^{--}$neutrophils that had been exposed to the same microenvironment within the host. $\mathrm{CD} 18^{-1-}$ and chimeric mice received 5-bromo-2'-deoxyuridine (BrdU; Sigma, St Louis, MO, USA) to label dividing cells in the BM (1 mg BrdU per $22 \mathrm{~g}$ body weight, given intraperitoneally). Chimeric mice were studied at least 10 weeks after reconstitution. The thymidine analog BrdU incorporates into DNA during S-phase in dividing cells and has been well studied as a nonradioactive alternative to tritiated thymidine in determining neutrophil kinetics in vivo. ${ }^{12-14}$ At the indicated times post-BrdU, blood was obtained through the inferior vena cava and BM cells collected by flushing the contents of dissected femurs with PBS containing 2 mM EDTA. Circulating leukocyte counts were determined using a hemocytometer and HemaStat-stained blood smears, or using a Hemavet counter (Drew Scientific, Oxford, CT, USA). To examine the role of CD18 in the proliferation of neutrophil progenitors, we harvested BM cells $2 \mathrm{~h}$ after BrdU administration.

\section{Staining of Samples and Flow Cytometry}

Blood and BM samples were stained with antibody to BrdU labeled with fluorescein isothiocyanate (FITC) and anti-Gr-1 antibody labeled with phycoerythrin (PE), as previously described. ${ }^{4}$ In experiments using chimeric animals, samples were incubated with biotin-conjugated antibody to CD45.1 or CD45.2, washed, and then incubated with streptavidinPE-Cy5 (all reagents obtained from BD Pharmingen, San Diego, CA, USA). Samples were read using a FACScan flow cytometer (BD Biosciences, San Jose, CA, USA), and data were processed using CellQuest (BD) and FCS Express (DeNovo Software, Thornhill, ON, Canada).

Leukocytes were gated according to their scatter characteristics, and neutrophils were identified within the leukocyte gate by high expression of Gr-1. Increasing surface expression of Gr-1 is correlated with granulocyte differentiation and maturation in the BM, whereas high Gr-1 expression in the circulation is confined to neutrophils. ${ }^{15,16}$ The percentage of Gr-1 + cells that incorporated BrdU was calculated. The absolute number of circulating BrdU-labeled neutrophils was obtained by multiplying the percentage of BrdU + neutrophils by the circulating neutrophil counts. In studies using chimeric mice, the number and proportion of WT vs $\mathrm{CD}^{-1-}$ (CD45.1 vs CD45.2) neutrophils that incorporated BrdU were determined. The ratio of WT/CD18 ${ }^{-1-}$ cells, the proportion of each genotype that was $\mathrm{BrdU}+$ at each time point, and the proportion of cells of either genotype that consisted of neutrophils were determined.

\section{HSC Isolation and Culture}

BM cells were obtained by flushing the femurs and tibia of 6to 8 -week-old mice with PBS containing $2 \%$ fetal calf serum (FCS; Invitrogen). After treatment with $10 \%$ normal rat serum and Fc block (BD Pharmingen), the cells were stained with PE-conjugated antibodies to CD3e, CD4, B220, Ter119, and Gr-1, FITC-conjugated anti-Sca-1, and allophycocyaninconjugated anti-c-kit (all antibodies obtained from $\mathrm{BD}$ Pharmingen) for $30 \mathrm{~min}$ at $4^{\circ} \mathrm{C}$ in the dark. The $\mathrm{BM}$ cell population that contains HSC, identified as lineage-negative, Sca-1 +, c-kit + (LSK), were sorted using FACSAria (BD Biosciences) into sterile tubes or multiwell plates containing $\alpha$-MEM with $20 \%$ FCS, murine IL-3 (20 ng/ml), IL-6 (50 ng/ $\mathrm{ml})$, G-CSF $(25 \mathrm{ng} / \mathrm{ml})$, GM-CSF $(10 \mathrm{ng} / \mathrm{ml})$, rat SCF $(50 \mathrm{ng} /$ $\mathrm{ml}$ ), $2 \mathrm{mM}$ L-glutamine, $100 \mathrm{U} / \mathrm{ml}$ penicillin, and $100 \mu \mathrm{g} / \mathrm{ml}$ streptomycin. Cultures were grown at $37^{\circ} \mathrm{C}$ with $5 \% \mathrm{CO}_{2}$. Cells were harvested at the indicated times and stained with PE-conjugated anti-Gr-1. Apoptosis was assessed using the TACS Annexin V-FITC detection kit (R\&D Systems). Staining with Annexin V and anti-Gr-1 was assessed by flow cytometry. Cell viability was assessed by Trypan blue exclusion. 


\section{Leukocyte Surface Markers}

Samples were incubated with various combinations of FITC-conjugated anti-CD45.2, PE-conjugated antibodies to $\mathrm{CD} 3, \mathrm{~B} 220$, or $\mathrm{Gr}-1$, or biotin-conjugated antibodies to CD45.1, CD11a, or c-kit (CD117), followed by incubation with streptavidin-conjugated PE-Cy5 (all reagents from BD Pharmingen).

\section{Statistics}

Data were compared using ANOVA, two-tailed $t$-test, nonparametric median, or Mann-Whitney $U$-test, as appropriate. $P$-value less than 0.05 was considered significant.

\section{RESULTS}

\section{Circulating G-CSF and Lung IL-17 mRNA in CD18 or ICAM-1 Deficiency}

Serum G-CSF and IL-17 levels have been reported to correlate with circulating neutrophil counts in mice deficient in CD18 or other leukocyte adhesion molecules, ${ }^{5,6}$ and IL-17 mRNA was elevated in lung and other tissues from these mutant mice. ${ }^{6}$ Hence, circulating G-CSF and lung IL-17 mRNA were measured in WT mice and in mice deficient in CD18 or ICAM-1, the major cellular counterreceptor for CD11/CD18 (Table 1). As previously described, circulating neutrophil counts were increased in both mutant mice, 16fold in $\mathrm{CD} 18^{-1-}$ mice and 4-fold in $\mathrm{ICAM}^{-1-}{ }^{-1}$ mice, compared to WT mice. Lung IL-17 mRNA increased over 16fold and plasma G-CSF increased 9-fold in CD18 ${ }^{-1-}$ compared with those in WT mice. IL-17 mRNA was detectable at

Table 1 Circulating neutrophil counts, plasma G-CSF, and lung IL-17 mRNA in samples from WT, CD18 ${ }^{-/-}$, and ICAM-1 ${ }^{-1-}$ mice

\begin{tabular}{|c|c|c|c|}
\hline & WT & $\mathrm{CD} 18^{-1-}$ & ICAM- $1^{-1-}$ \\
\hline $\begin{array}{l}\text { Circulating neutrophil counts } \\
\left(\times 10^{6} \text { per } \mathrm{ml} \text { blood }\right)\end{array}$ & $0.4 \pm 0.1$ & $6.3 \pm 0.3^{* \dagger \dagger}$ & $1.5 \pm 0.2^{*}$ \\
\hline Plasma G-CSF (pg/ml plasma) & $62 \pm 4$ & $541 \pm 26^{*}$ & $95 \pm 12$ \\
\hline Lung IL-17 mRNA $\left(C_{T}\right)$ & $\begin{array}{l}>40 \text { (in } 3 \text { of } 5 \\
\text { mice) } 36.6,38.2\end{array}$ & $33.6 \pm 0.6^{*, \dagger}$ & $36.9 \pm 0.5^{*}$ \\
\hline
\end{tabular}

Neutrophil counts were determined as described in Materials and Methods section. Plasma was obtained from healthy 6 - to 8-week-old female mice, and the amount of G-CSF measured by ELISA (R\&D Systems, Minneapolis, MN, USA) according to the manufacturer's instructions. Total RNA was obtained from the lungs of healthy mice, and IL-17 expression measured by real-time RT-PCR. IL17 message was normalized to $28 \mathrm{~S}$ mitochondrial ribosomal RNA expression in each sample. The amount of IL-17 message in each sample is expressed as $C_{T}$, defined as the cycle at which IL-17 message is amplified to a level above baseline. Each cycle difference in $C_{\mathrm{T}}$ is approximately a twofold difference in the amount of IL-17 template. IL-17 message was undetectable at up to 40 PCR cycles in three out of five WT mice. The $C_{T}$ values obtained for the remaining WT mice are shown. Data are expressed as mean \pm s.e.m. $(n=5)$ except in IL-17 mRNA for WT mice. ANOVAs were used to compare neutrophil counts and G-CSF levels, and nonparametric median test and Mann-Whitney $U$-test to compare IL-17 mRNA $C_{\mathrm{T}}$.

${ }^{\star} P<0.05$ vs WT; ${ }^{\dagger} P<0.05$ vs ICAM $-1^{-1-}$. low levels in all samples from ICAM-1 ${ }^{-1-}$ mice, whereas IL17 mRNA was undetectable after 40 PCR cycles in three out of five WT mice and present at low levels in two WT mice, suggesting that a small increase in IL-17 was present in the ICAM-1 ${ }^{-l-}$ mice that was not sufficient to result in detectable changes in G-CSF. Thus, elevated G-CSF and IL-17 levels are associated with extreme neutrophilia in $\mathrm{CD} 18^{-1-}$ mice, likely resulting from the dysfunctional neutrophils causing a defect in host defense and subsequent neutrophilia; and normal and slightly increased levels of G-CSF and IL-17 are associated with the fourfold increase in circulating neutrophils in ICAM- $1^{-/-}$mice.

\section{Neutrophil Kinetics}

The increase in circulating G-CSF in $\mathrm{CD} 18^{-1-}$ mice would be sufficient in itself to cause alterations in neutrophil kinetics, because G-CSF is a major cytokine that regulates neutrophil production and release from the BM. In contrast, the fourfold increase in neutrophil counts observed in ICAM-1 $1^{-1-}$ mice, in the presence of normal G-CSF levels and only slightly increased levels of IL-17 mRNA, and the absence of spontaneous infections in ICAM-1 null mice, suggest that neutrophilia can result through alterations in the CD11/C18ICAM-1 signaling axis due to defects other than those induced by abnormal host defense. On the basis of these observations and previous studies from our laboratory and other investigators, we focused on understanding intrinsic roles of CD18 in the maturation and release of neutrophils from the BM.

To begin to determine whether CD18 has a direct function in regulating the production and release of neutrophils from the BM, we studied neutrophil kinetics in lethally irradiated WT animals reconstituted with a 60:40 mixture of WT and $\mathrm{CD} 18^{-/-}$fetal liver cells. This approach has the advantage of allowing comparison of WT and $\mathrm{CD} 18^{-/-}$neutrophils that were present in the same microenvironment within chimeric mice. Furthermore, the possible effect of host defense defects on the kinetics of $\mathrm{CD} 18^{-1-}$ neutrophils can be excluded using this approach, because the presence of WT leukocytes in the chimeric mice confers protection to the chimeric mice.

Eleven weeks after reconstitution, the average neutrophil count in chimeric animals was $3.5 \pm 0.2 \times 10^{6}$ per ml $(n=21)$. In comparison, the average neutrophil count in untransplanted $\mathrm{CD} 18^{-/-}$mice was about four times higher $\left(14.8 \pm 1.3 \times 10^{6}\right.$ per $\mathrm{ml}, \quad n=50, P<0.001$ independent $t$-test). The percentage of Gr-1+ cells in the BM was significantly greater in the $\mathrm{CD} 18^{-1-}$ mice compared with that of chimeric mice ( $84 \pm 1$ vs $59 \pm 1 \%$, respectively, $P<0.001$ ).

Compared with WT neutrophils in chimeric animals, a lower percentage of circulating $\mathrm{CD} 18^{-/-}$neutrophils were labeled with BrdU at 12 and $24 \mathrm{~h}$ in $\mathrm{CD} 18^{-1-}$ and chimeric mice and at $48 \mathrm{~h}$ in the chimeric mice (Figure 1a). At these early time points, the $\mathrm{BrdU}+$ neutrophils in the circulation are likely derived from precursors that took up BrdU during the S-phase of their last division before entering the 

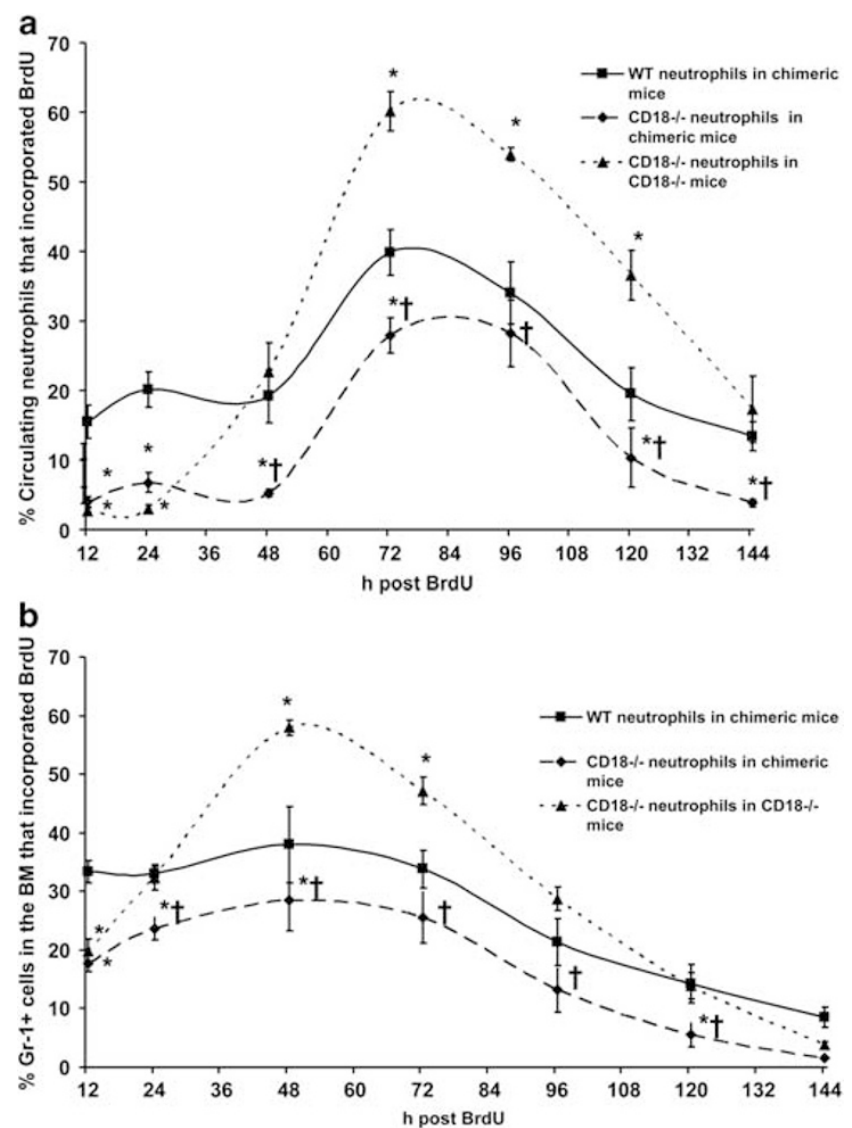

Figure 1 (a) The emergence of BrdU + circulating neutrophils in chimeric and untransplanted $\mathrm{CD} 18^{-/-}$mice after BrdU administration. Chimeric mice were made by reconstituting lethally irradiated C57BL/6-CD45.2 hosts with a 60:40 mixture of WT C57BL/6-CD45.1 and CD18 ${ }^{-1-}$ (CD45.2) fetal liver cells. Mice received a single intraperitoneal injection of $\mathrm{BrdU}$ and were killed at the indicated times. Blood and BM samples were collected and stained with antibodies to BrdU and the neutrophil marker Gr-1. Samples from chimeric mice were also stained with anti-CD45.1 antibody to distinguish WT and $\mathrm{CD} 18^{-1-}$ leukocytes. The proportion of circulating neutrophils that were BrdU-labeled over time was determined by flow cytometry. The delayed release of $\mathrm{CD} 18^{-/-}$neutrophils at 12 and $24 \mathrm{~h}$ after injection of BrdU was still present in chimeric mice, but the enhanced release of $\mathrm{CD} 18^{-/-}$neutrophils by $72 \mathrm{~h}$ was completely prevented. (b) The proportion of $\mathrm{BrdU}+\mathrm{Gr}-1+$ cells in the $\mathrm{BM}$ of $\mathrm{CD} 18^{-/-}$and chimeric mice. $\mathrm{BM}$ cells from $\mathrm{CD} 18^{-/-}$and chimeric mice were collected and stained the indicated times after BrdU administration. Neutrophils and their late-stage precursors were identified by their surface expression of $\mathrm{Gr}-1$, and the percentage of $\mathrm{Gr}-1+$ cells that incorporated BrdU was determined by flow cytometry. Data are presented as mean percentage of BrdU $+\mathrm{Gr}-1+$ cells \pm s.e.m. ( $n=4-10$ for each group at each time point). ${ }^{*} P<0.05$ compared to WT Gr-1 + cells in chimeric mice; ${ }^{\dagger} P<0.05$ compared to $\mathrm{CD} 18^{-/-}$mice (ANOVA).

postmitotic maturation phase and subsequent release. These data suggest a direct function for CD18 in regulating maturation of postmitotic myeloid cells in the $\mathrm{BM}$ or in the release of the most mature neutrophils into the circulation, because the presence of WT leukocytes did not correct this defect in $\mathrm{CD} 18^{-1-}$ neutrophils. There was a steep rise in both the proportion and number of neutrophils that incorporated
BrdU after $24 \mathrm{~h}$ in the $\mathrm{CD} 18^{-/-}$mice (Figure 1a and Table 2). In contrast, the proportion of $\mathrm{CD} 18^{-1-}$ circulating neutrophils that were $\mathrm{BrdU}+$ in chimeric mice was consistently lower compared with that of WT neutrophils in chimeric mice or with mutant neutrophils in $\mathrm{CD} 18^{-/-}$mice. Thus, the enhanced release of neutrophils after an initial delay observed in $\mathrm{CD} 18^{-1-}$ mice may be due to indirect effects that can be prevented by the presence of WT neutrophils in the chimeric mice.

In the $\mathrm{BM}$, a rapid rise in the proportion of BrdU-labeled $\mathrm{Gr}-1+$ cells from 12 to $48 \mathrm{~h}$ is observed in the $\mathrm{CD} 18^{-1-}$ mice but it is absent in chimeric mice (Figure 1b). This finding suggests that extrinsic factors resulting from defects in host defense that stimulate the BM, rather than intrinsic defects in $\mathrm{CD} 18^{-/-}$neutrophils, result in accelerated neutrophil development and maturation in the $\mathrm{BM}$ of $\mathrm{CD} 18^{-1-}$ mice. In the $\mathrm{BM}$ of chimeric mice, a consistently lower percentage of the $\mathrm{CD} 18^{-/-} \mathrm{Gr}-1+$ cells incorporated BrdU compared with that of WT Gr-1 + cells. Because Gr-1 can be expressed both by neutrophils and by their late-stage precursors in the BM, we sought to determine the fraction of $\mathrm{Gr}-1+\mathrm{BM}$ cells undergoing DNA synthesis. The proportion of BrdU-labeled cells in the BM of chimeric animals was measured $2 \mathrm{~h}$ after BrdU administration. The proportion of BrdU-labeled WT $\mathrm{Gr}-1+$ cells varied in two separate experiments, but in each mouse the proportion of $\mathrm{Gr}-1+$ cells that were BrdU-labeled was consistently lower in the CD18 ${ }^{-1-}$ than the WT population (Table 3). Thus, increased proliferation of late-stage neutrophil precursors does not account for the increased neutrophil production observed in the absence of CD18.

Although WT recipients were given a 60:40 mixture of $\mathrm{WT} / \mathrm{CD} 18^{-1-}$ fetal liver cells, the number of $\mathrm{CD} 18^{-1-}$ neutrophils in the circulation of chimeric animals was 2-3 times that of WT neutrophils, giving an average WT to CD18 ratio of 29:71 (Figure 2a). The ratio of WT/CD18 ${ }^{-1-} \mathrm{Gr}-1+$ cells in the BM was 30:70 (Figure 2b). Furthermore, the percentage of $\mathrm{CD} 18^{-1-}$ leukocytes that were neutrophils was greater than the percentage of WT leukocytes that were neutrophils (Figure 2c). The increase in the number and proportion of $\mathrm{CD} 18^{-1-}$ neutrophils was observed even though normal numbers of WT leukocytes were present in the chimeric mice, suggesting that the alteration in neutrophil production was not caused by defects in host defense. These data suggest that CD18 directly regulates the numbers of neutrophil precursors and determines commitment of progenitors to the neutrophil lineage.

\section{LSK Cells in the BM of WT and CD18 ${ }^{-I-}$ Mice}

The increase in the proportion of terminally differentiated cells in the $\mathrm{BM}$ of $\mathrm{CD} 18^{-/-}$mice led us to wonder if $\mathrm{CD} 18$ deficiency resulted in a decrease in the number of more primitive progenitors. To determine if $\mathrm{CD} 18$ can regulate the number of hematopoietic cells early during their development, we compared the fraction of BM cells that are early-stage progenitors in $\mathrm{CD}_{1} 8^{-/-}$and WT mice. The 
Table 2 The number of circulating neutrophils that incorporated BrdU in chimeric and CD18 ${ }^{-1-}$ mice

\begin{tabular}{|c|c|c|c|}
\hline $\begin{array}{l}\text { Hours after BrdU } \\
\text { administration }\end{array}$ & $\begin{array}{l}\text { BrdU+ WT neutrophils in chimeric } \\
\text { mice }\left(\times 10^{6} \text { per } \mathrm{ml} \text { blood }\right)\end{array}$ & $\begin{array}{c}\text { BrdU+CD18 }{ }^{-1-} \text { neutrophils in } \\
\text { chimeric mice }\left(\times 10^{6} \text { per } \mathrm{ml} \text { blood }\right)\end{array}$ & $\begin{array}{c}\text { BrdU+CD18 } 8^{-1-} \text { neutrophils in } \\
\mathrm{CD} 18^{-1-} \text { mice }\left(\times 10^{6} \text { per } \mathrm{ml} \text { blood }\right)\end{array}$ \\
\hline 24 & $0.25 \pm 0.06$ & $0.14 \pm 0.04$ & $0.51 \pm 0.1$ \\
\hline 48 & $0.24 \pm 0.08$ & $0.12 \pm 0.01$ & $4.5 \pm 1.2^{\star}$ \\
\hline 120 & $0.17 \pm 0.03$ & $0.26 \pm 0.15$ & $4.1 \pm 0.7^{*}$ \\
\hline 144 & $0.09 \pm 0.02$ & $0.07 \pm 0.02$ & $2.2 \pm 0.7^{\star}$ \\
\hline
\end{tabular}

Chimeric mice were made by reconstituting lethally irradiated WT mice with a 60:40 mixture of WT and CD18 ${ }^{-/-}$fetal liver cells. Untransplanted CD18 ${ }^{-/-}$mice and chimeric mice were given BrdU to label dividing cells in their BM, and blood and BM samples were harvested at the indicated time points after BrdU administration. Circulating neutrophil counts were determined, and the percentage of circulating WT or CD18 $8^{-1-}$ neutrophils that incorporated BrdU was determined by flow cytometry. The number of BrdU-labeled circulating neutrophils was obtained by multiplying the circulating neutrophil counts by the proportion of circulating neutrophils that were BrdU-labeled.

${ }^{\star} P<0.05$ vs WT or $\mathrm{CD} 18^{-/-}$neutrophils in chimeric mice (ANOVA).

Table 3 BM cells in chimeric mice $2 \mathrm{~h}$ after BrdU administration

\begin{tabular}{|c|c|c|}
\hline Group & $\begin{array}{l}\text { Experiment } 1 \\
\text { (154 days } \\
\text { after BMT) }\end{array}$ & $\begin{array}{l}\text { Experiment } 2 \\
\text { (190 days } \\
\text { after BMT) }\end{array}$ \\
\hline $\mathrm{Gr}-1+\mathrm{BM}$ cells that are $\mathrm{CD} 18^{-/-}(\%)$ & $71.1 \pm 5.6$ & $69.7 \pm 8.1$ \\
\hline WT Gr-1+ cells that are BrdU+ (\%) & $34.2 \pm 5.1^{*}$ & $15.9 \pm 3.2$ \\
\hline $\mathrm{CD} 18^{-/-} \mathrm{Gr}-1+$ cells that are BrdU+ (\%) & $8.4 \pm 0.8$ & $8.9 \pm 1.7$ \\
\hline $\begin{array}{l}\text { Circulating WT neutrophil counts } \\
\left(\times 10^{6} \text { per } \mathrm{ml}\right)\end{array}$ & $1.2 \pm 0.3$ & $0.9 \pm 0.3$ \\
\hline $\begin{array}{l}\text { Circulating } \mathrm{CD} 18^{-/-} \text {neutrophil counts } \\
\left(\times 10^{6} \text { per } \mathrm{ml}\right)\end{array}$ & $3.8 \pm 1.1$ & $3.0 \pm 1.0$ \\
\hline
\end{tabular}

To determine the fraction of hematopoietic cells undergoing DNA synthesis, we killed mice whose hematopoietic systems had been reconstituted with a 60:40 mixture of WT and CD18 ${ }^{-1-}$ fetal liver cells $2 \mathrm{~h}$ after BrdU administration. The expression of Gr-1 and CD45.1, and incorporation of BrdU by BM cells were determined by flow cytometry. Data represent mean \pm s.e.m. $(n=4)$. ${ }^{*} P<0.05$ vs $\mathrm{CD} 18^{-1-}$ (Student's $t$-test).

lineage-negative, Sca-1 + , c-kit + (LSK) fraction is enriched for HSCs that give rise to all the hematopoietic lineages, whereas the lineage-negative, c-kit + , and Sca- $1-$ fraction contains more mature hematopoietic progenitors. The proportion of LSK cells in the BM of CD18 $8^{-l-}$ mice was greater compared to that in WT animals (Figure 3a). The proportion of lineagenegative, c-kit + , Sca-1- progenitors was also increased in the $\mathrm{BM}$ of $\mathrm{CD} 18^{-/-}$mice compared to WT (Figure 3b). Thus, $\mathrm{CD} 18$ deficiency appears to result in a greater number of terminally differentiated leukocytes (mainly granulocytes) with no diminution in the number of primitive progenitors.

\section{Neutrophils Derived from LSK Cells In Vitro}

The increase in the number of granulocytes in the BM may be due to increased proliferation and/or increased survival of neutrophil progenitors. To determine if $\mathrm{CD} 18$ could regulate the survival of neutrophil progenitors, we grew LSK cells from WT and CD18 $8^{-1-}$ mice in media without stromal cells or any defined exogenous extracellular matrix. The total number of Gr-1 + cells and the number that bound Annexin $\mathrm{V}$, a measure of early apoptosis, were evaluated. After 14 days in culture, the number of $\mathrm{Gr}-1+$ cells was greater in the $\mathrm{CD} 18^{-1-}$ cultures, and this difference was due to a greater number of Annexin V- Gr-1 + cells (Figure 4). These data suggest that $\mathrm{CD} 18$ may regulate apoptosis of neutrophils or their precursors.

\section{CD18 Regulates Leukocyte Distribution and Survival In Vivo}

To determine if CD18 has a primary function in regulating the survival of neutrophils or their precursors and in modulating the lineage distribution of hematopoietic cells in vivo, we reconstituted lethally irradiated WT recipients with a 1:4 or 4:1 mixture of WT and CD18 ${ }^{-1-}$ fetal liver cells. We reasoned that differences in the survival or distribution of WT and $\mathrm{CD} 18^{-1-}$ cells that are present regardless of the ratio of reconstituting WT and $\mathrm{CD} 18^{-1-}$ fetal liver cells are likely to be due to the intrinsic roles of CD18 in hematopoiesis.

To verify that the observed differences are not due to a difference in the number of HSCs in the fetal livers of WT and $\mathrm{CD} 18^{-1-}$ mice, we determined the proportion of total fetal liver cells that were lineage-negative, $\mathrm{c}$-kit + , and Sca- $1+$ (LSK). The proportion of LSK cells was similar in the WT and $\mathrm{CD} 18^{-l-}$ fetal liver cells $(0.07$ vs $0.09 \%$, respectively). 

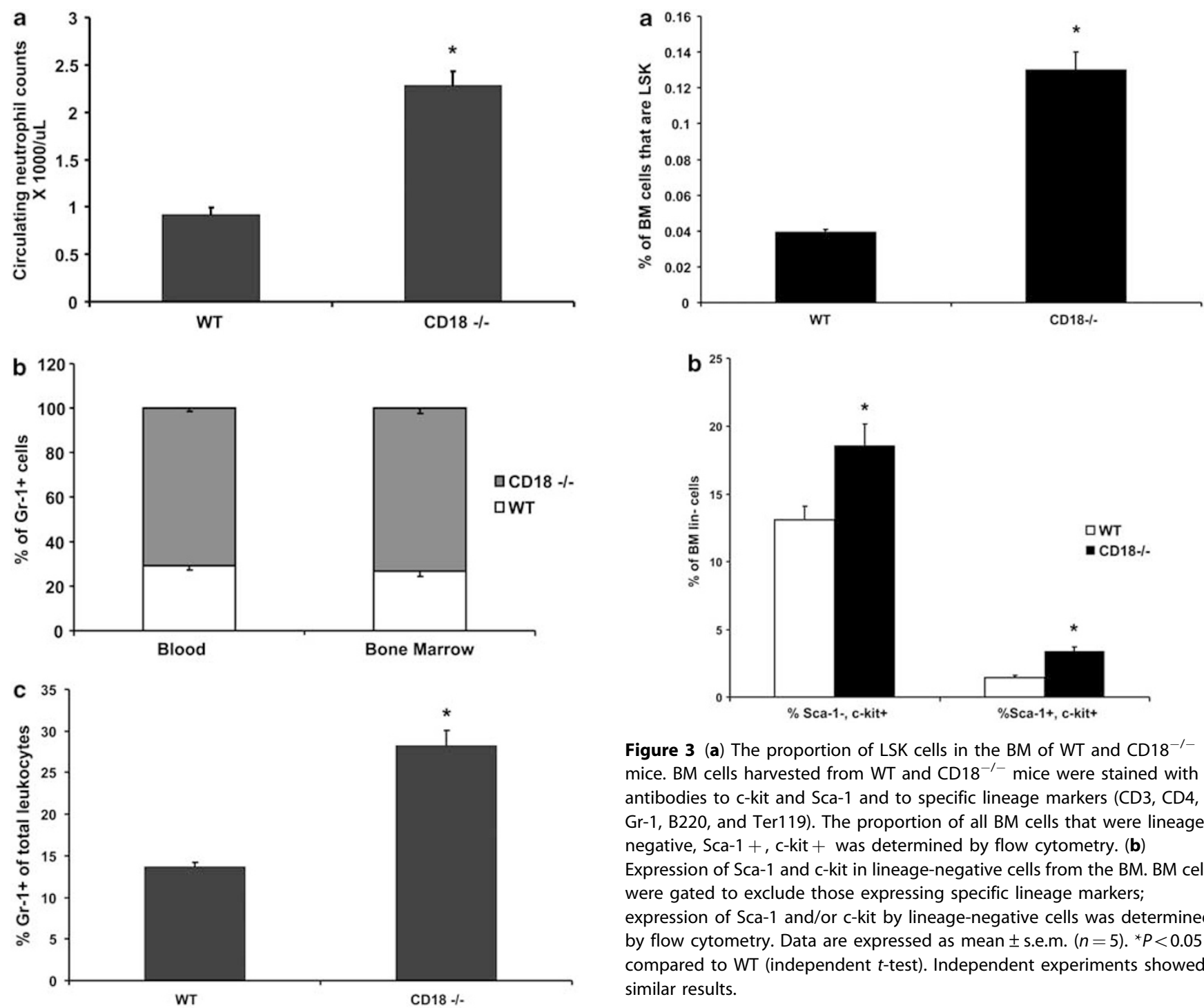

Figure 2 (a) A disproportionate number of circulating neutrophils in chimeric animals are $\mathrm{CD} 18^{-/-}$. Data were collected at 11 and 15 weeks after lethal irradiation and reconstitution of WT hosts with a 60:40 mixture of WT/CD $18^{-/-}$fetal liver cells. Neutrophils were identified by high surface expression of Gr-1 and their genotype ascertained by staining with anti-CD45.1 or anti-CD45.2 antibody (please see Materials and Methods section). The numbers of WT or $\mathrm{CD} 18^{-1-}$ neutrophils were obtained by multiplying the percentage of WT or mutant Gr-1 + leukocytes by the circulating neutrophil counts. The columns represent the mean \pm s.e.m. $(n=35) .{ }^{*} P<0.05$ vs WT (ANOVA). (b) The ratio of WT/CD $18^{-/-} \mathrm{Gr}-1+$ cells is about 30:70 in the blood and BM. Surface expression of CD45.1 or CD45.2 and $\mathrm{Gr}-1$ by circulating and BM leukocytes from each chimeric mouse was determined by flow cytometry. Columns indicate mean \pm s.e.m. $(n=35)$. (c) The proportion of circulating leukocytes that are neutrophils is at least two times higher in the $\mathrm{CD}_{1} 8^{-/-}$than in the WT leukocytes. The percentage of circulating WT or $\mathrm{CD} 18^{-/-}$leukocytes that expressed the neutrophil marker Gr-1 was determined in blood samples from each chimeric mouse, as described in the text. The bars represent the mean percentage \pm s.e.m. $(n=35) .{ }^{\star} P<0.05$ (independent $t$-test). 


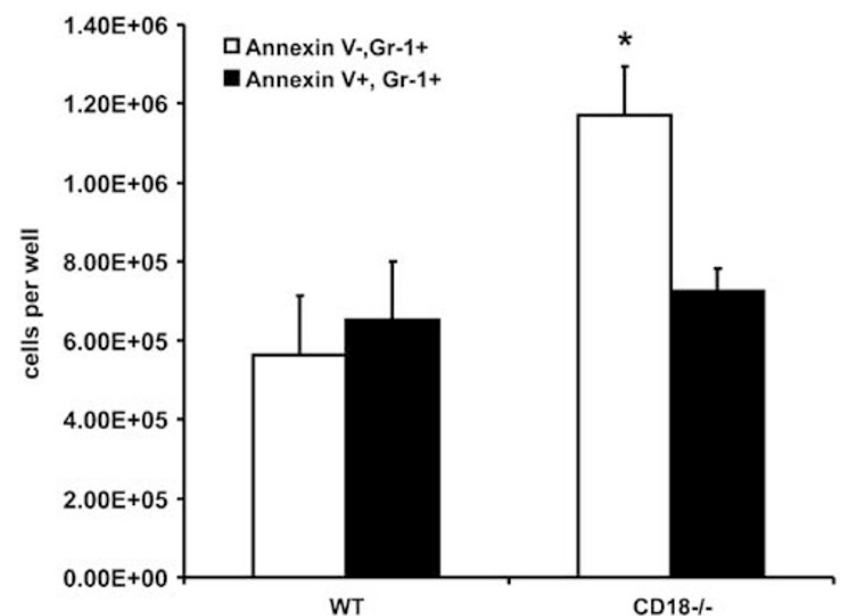

Figure 4 The number of Gr-1 + cells grown from LSK cells in stroma-free culture. Isolated pure LSK cells were cultured for 14 days in serumcontaining medium supplemented with IL-3, IL-6, SCF, G-CSF, and GM-CSF without other matrix or cells. Cells were obtained from three replicate wells of each genotype and stained with Annexin V and anti-Gr-1 as described in Materials and Methods section. The number of cells in each well was determined using a hemocytometer. Data are expressed as mean \pm s.e.m. of three replicates. ${ }^{*} P<0.05$, independent $t$-test.

possibility is that CD18 may regulate apoptosis in rarer, more primitive hematopoietic cells that proliferate and give rise to Gr-1 + populations, thus magnifying the effect of CD18 deficiency on the number of terminally differentiated cells.

Consistent with data obtained from the mice reconstituted with a 60:40 mixture of WT and $\mathrm{CD} 18^{-1-}$ donor cells, the proportion of $\mathrm{Gr}-1+$ cells in the blood and $\mathrm{BM}$ that were derived from $\mathrm{CD} 18^{-/-}$stem cells was higher than predicted based on the ratio of WT and mutant fetal liver cells that were given to reconstitute the recipients' hematopoietic systems (Figure 6a and b). Surprisingly, the percentage of B cells that were $\mathrm{CD} 18^{-1-}$ was also higher than predicted based on the ratio of $\mathrm{CD} 18^{-1-}$ cells given to reconstitute. Conversely, the proportion of $\mathrm{CD} 3+$ cells that were $\mathrm{CD} 18^{-1-}$ was lower than expected. The data indicate that lacking CD18 causes expansion of granulopoiesis and perhaps B-lymphocyte production, even when only $20 \%$ of the stem cells are CD18 null (Figure $6 \mathrm{a}$ and $\mathrm{b}$ and Table 4 ). However, our data do not rule out alterations in the trafficking of $\mathrm{CD} 18^{-1-}$ lymphocytes in the BM and other tissues, which may account for the increase in the proportion of $\mathrm{CD} 18^{-1-} \mathrm{B}$ cells.

Lineage distribution of $\mathrm{CD}_{1} 8^{-1-}$ leukocytes in the blood and BM is altered compared with WT leukocytes (Figure $7 \mathrm{a}$ and $\mathrm{b}$ ). The proportions of $\mathrm{CD} 18^{-/}$cells in the blood that were Gr-1 + or B220 + were significantly higher compared with that of WT cells (Figure 7a). The proportion of $\mathrm{CD} 18^{-I-}$ cells that were $\mathrm{CD} 3+$ was lower compared with that of WT cells. In the BM, the proportion of $\mathrm{CD} 18^{-1-}$ cells that were Gr-1 + was higher than that in WT cells (Figure $7 \mathrm{~b}$ ). The proportion of $\mathrm{CD} 18^{-1-}$ cells that were $\mathrm{B} 220+$ was significantly lower than the proportion of WT cells that were

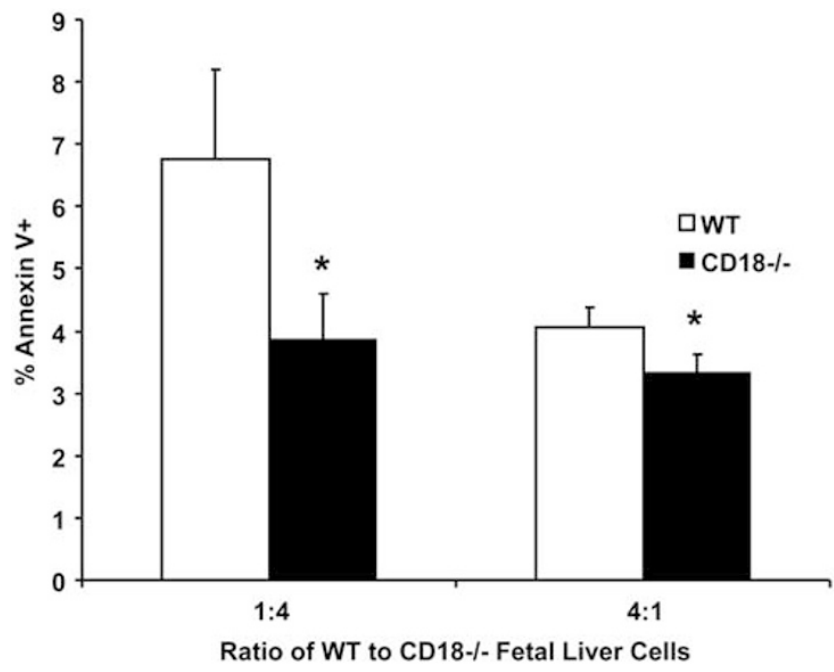

Figure 5 The proportion of Gr-1 + cells in the BM that were Annexin V + . Lethally irradiated WT recipients were reconstituted with a 1:4 or 4:1 mixture of WT and CD18 ${ }^{-/-}$fetal liver cells. Ten and 14 weeks after the transplant, BM cells were harvested from the femurs of chimeric mice, and stained with Annexin V and antibodies to Gr-1 and CD11a. The percentage of WT $(\mathrm{CD} 11 \mathrm{a}+)$ and $\mathrm{CD} 18^{-1-}(\mathrm{CD} 11 \mathrm{a}-) \mathrm{Gr}-1+$ cells that stained with Annexin $\mathrm{V}$ was determined by flow cytometry. After reconstitution with either $1: 4$ or $4: 1 \mathrm{WT} / \mathrm{CD} 18^{-/-}$fetal liver cells, the proportion of Gr-1 + cells that was apoptotic was less in $\mathrm{CD} 18^{-1-}$ BM cells than in WT BM cells. The proportion of WT Gr-1 + cells that were apoptotic (Annexin V + ) tended to be higher in the mice that received a 1:4 mixture of WT/CD18 ${ }^{-1-}$ fetal liver cells compared to that in the mice that received a $4: 1$ mixture, but this difference did not reach statistical significance $(P=0.12$, independent $t$ test). Data are expressed as mean \pm s.e.m. $(n=6) .{ }^{\star} P<0.05$ vs WT cells in the same group (paired $t$-test).

B220 + in the 1:4 group, but not in the 4:1 group. Taken together, these data show a function for CD18 in regulating proliferation and lineage commitment of hematopoietic progenitors/precursors.

\section{DISCUSSION}

The ability of WT leukocytes to suppress neutrophilia in $\mathrm{CD} 18^{-1-}$ mice suggests that indirect extrinsic effects are largely responsible for the neutrophilia observed in CD18 deficiency. ${ }^{4,5}$ These defects reflect the defects in host defense present in mice and humans with CD18 deficiency that are due to the many abnormal functions these neutrophils exhibit. ${ }^{3}$ The inability of neutrophils deficient in CD18 to respond and resolve the inflammatory response then results in enhanced neutrophil production in the BM. Stark et $a l^{6}$ showed that this inability of mutant neutrophils to migrate into tissues enhances neutrophil production in the BM through a pathway that involves IL-23, IL-17, and G-CSF. Plasma G-CSF concentration and lung IL-17 mRNA are significantly higher in $\mathrm{CD} 18^{-/-}$mice compared with that in WT mice, supporting the view that elevated IL-17 and G-CSF contribute to the increased production of neutrophils in these mice. ${ }^{5,6}$ Stark et $a l^{6}$ showed that decreased phagocytosis 
a

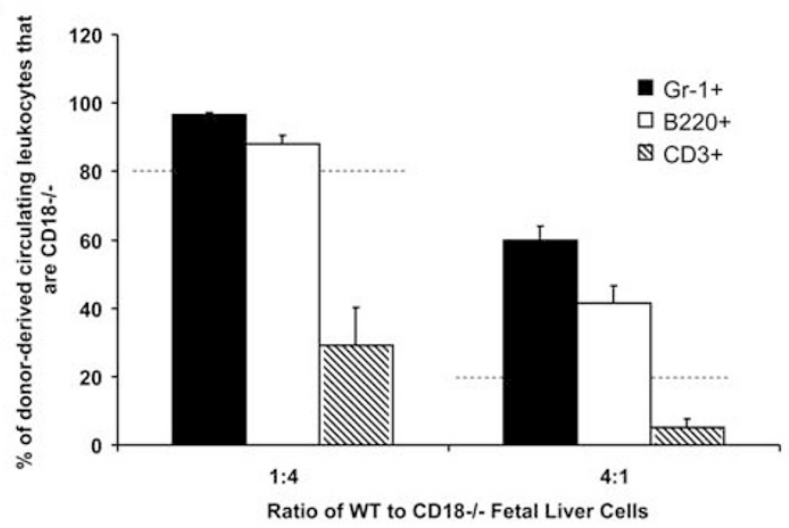

b

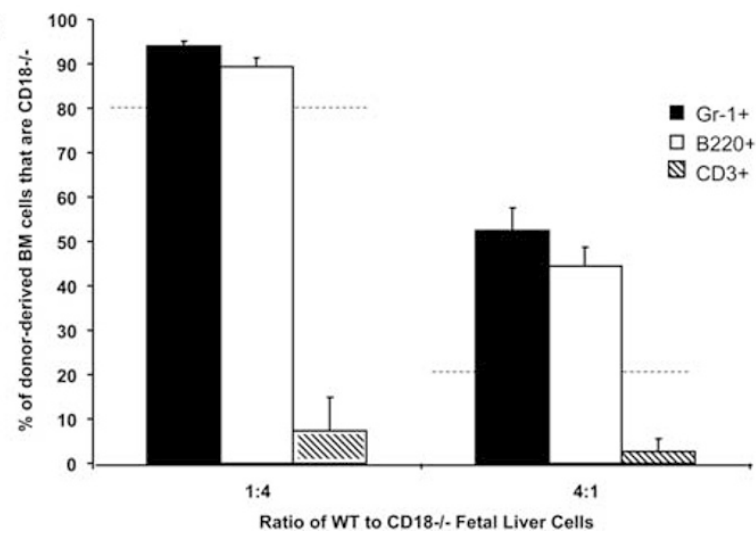

Figure 6 (a) The proportion of donor-derived circulating leukocytes that were $\mathrm{CD} 18^{-1-}$. (b) The proportion of donor-derived leukocytes in the BM that were $\mathrm{CD} 18^{-/-}$. Blood and BM samples were obtained from C57BL/6CD45.2 hosts reconstituted with a 1:4 or 4:1 mixture of C57BL/6-CD45.1 and $\mathrm{CD} 18^{-/-}$fetal liver cells at least 8 weeks after transplant. Donor-derived leukocytes were identified as either WT (CD45.1/CD11a + ) or CD18 ${ }^{-/-}$ (CD45.2/CD11a-). The percentage of donor-derived neutrophils $(\mathrm{Gr}-1+)$, $B$ cells $(B 220+)$, and T cells $(C D 3+)$ that were derived from $\mathrm{CD}_{18} 8^{-1-}$ stem cells (CD11a-) was determined by flow cytometry. Dashed lines indicate the expected ratio of $\mathrm{CD} 18^{-/-}$cells in each population based on the initial proportion of $\mathrm{CD} 18^{-/-}$cells in the transplant ( $80 \%$ in the $1: 4$ group and $20 \%$ in the $4: 1$ group). Data are expressed as mean \pm s.e.m. $(n=6-7)$.

of apoptotic neutrophils results in increased IL-23 production by tissue macrophages, leading to increased IL-17 production by tissue-resident $\mathrm{T}$ cells, subsequent G-CSF production, and chronic stimulation of the BM. Mice that are doubly deficient in IL-23 and CD18 have slightly lower neutrophil counts than mice lacking CD18 alone, indicating a function for this cytokine in regulating neutrophil production, although the values are still 6- to 8-fold higher than WT mice. ${ }^{17}$ In our studies, the presence of normal numbers of WT leukocytes significantly reduced the total number of neutrophils in the blood and BM of chimeric mice, but did not correct the disproportionate number of CD18-deficient neutrophils present in these chimeric mice, suggesting CD18 may have an intrinsic function in regulating neutrophil production in the BM (irrespective of the presence of WT
Table 4 Circulating donor-derived leukocyte counts of each genotype in chimeric mice

\begin{tabular}{|c|c|c|c|c|}
\hline \multirow[t]{2}{*}{$\begin{array}{l}\text { Leukocyte } \\
\text { population }\end{array}$} & \multicolumn{2}{|c|}{$\begin{array}{l}\text { 1:4 WT/CD18 }{ }^{-/-} \text {donor } \\
\text { cells }\left(\times 10^{6} \text { per } \mathrm{ml} \text { blood }\right)\end{array}$} & \multicolumn{2}{|c|}{$\begin{array}{l}\text { 4:1 WT/CD18 }{ }^{-/-} \text {donor } \\
\text { cells }\left(\times 10^{6} \text { per } \mathrm{ml} \text { blood }\right)\end{array}$} \\
\hline & WT & $\mathrm{CD} 18^{-/-}$ & WT & $\mathrm{CD} 18^{-/-}$ \\
\hline Neutrophils & $0.13 \pm 0.04$ & $5.3 \pm 1.6^{*}$ & $1.0 \pm 0.20$ & $1.8 \pm 0.48^{\dagger}$ \\
\hline B lymphocytes & $0.66 \pm 0.13$ & $6.9 \pm 2.2^{*}$ & $3.2 \pm 0.61$ & $2.4 \pm 0.71$ \\
\hline T lymphocytes & $0.73 \pm 0.15$ & $0.5 \pm 0.22$ & $1.6 \pm 0.30$ & $0.1 \pm 0.04^{*}$ \\
\hline
\end{tabular}

Circulating leukocyte counts were determined in chimeric mice 10-14 weeks after reconstitution. Total leukocyte counts were determined using a hemocytometer. Leukocyte classes were identified by surface expression of Gr-1 (neutrophils), B220 (B lymphocytes), and CD3 (T lymphocytes) and leukocyte genotype was determined by staining with antibodies to CD45.2 and CD11a. Expression of surface markers was determined by flow cytometry. Data are expressed as mean \pm s.e.m. $(n=6-7)$.

${ }^{*} P<0.05$ and ${ }^{\dagger} P=0.05$ vs WT cells in the same group (paired $t$-test).
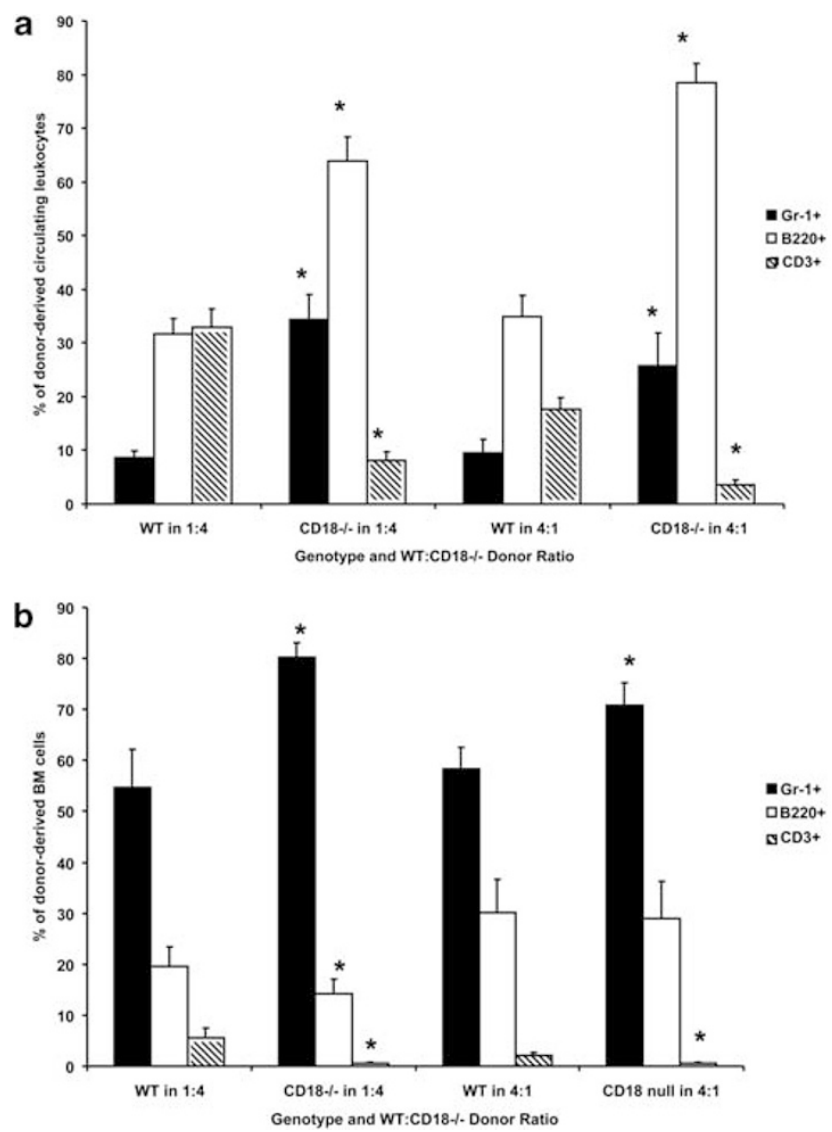

Figure 7 (a) Lineage distribution of donor-derived circulating leukocytes. (b) Lineage distribution of donor-derived BM leukocytes. The percentage of WT or $\mathrm{CD} 18^{-/-}$donor-derived leukocytes that were neutrophils/ granulocytes $(\mathrm{Gr}-1+)$, B cells (B220 + ), or T cells $(\mathrm{CD} 3+)$ was determined by flow cytometry. Data are expressed as mean \pm s.e.m. $(n=6-7) .{ }^{*} P<0.05$ $v s$ WT in the same group (paired $t$-test). 
leukocytes that can migrate to the tissues), which may contribute to the neutrophilia.

Mice deficient in ICAM-1, the major cellular ligand of CD11/CD18, have circulating neutrophil counts that are several-fold higher than those observed in WT mice. Intriguingly, circulating G-CSF and lung IL-17 mRNA in ICAM $-1^{-1-}$ mice are similar or only slightly elevated compared with those in WT mice. The absence of spontaneous infections in ICAM-1 ${ }^{-1-}$ mice suggests that CD18-dependent host defense responses can occur through an alternative ligand, but that CD18-mediated regulation of neutrophil development may require ICAM-1.

Engagement of CD11/CD18 on mature neutrophils has been reported to induce either survival or apoptosis depending on the stimulus, the presence of cytokines, and other cues. ${ }^{18}$ Weinmann et $a l^{7}$ have shown that apoptosis is delayed in circulating neutrophils from $\mathrm{CD} 18^{-/-}$mice, and that this delay is abolished in $\mathrm{CD}_{1} 8^{-/-}$neutrophils obtained from chimeric mice transplanted with WT and $\mathrm{CD} 18^{-1-} \mathrm{BM}$. Consistent with this finding by Weinmann et al, our data show that the decline in the percentage of BrdU $+\mathrm{WT}$ and $\mathrm{CD} 18^{-1-}$ neutrophils in the circulation of chimeric mice is similar. This delay in apoptosis of circulating neutrophils thus appears to be a consequence of extrinsic factors that can be corrected by the presence of WT cells. Interestingly, after reconstitution with either a 1:4 or 4:1 mixture of WT/CD18 ${ }^{-/-}$ fetal liver cells, the proportion of Gr-1 + cells in the BM that was apoptotic was less in CD18 cells than in WT BM cells. Whether this population of apoptotic Gr-1 + cells in the BM comprises late-stage Gr-1 expressing neutrophil precursors and/or effete neutrophils that are being cleared from the circulation by returning to the BM is not known. Whether the CD18-mediated signals that control apoptosis in neutrophils from the periphery are similar to those that operate in myeloid precursors and neutrophils from the BM remain to be determined. Apoptosis was decreased in Gr-1 + cells derived from $\mathrm{CD} 18^{-I-}$ HSCs that were isolated ex vivo and cultured in the absence of stromal cells or defined extracellular matrix, suggesting that the effect of CD18 may be independent of its function in mediating leukocyte adhesion to receptors on stromal cells or to extracellular matrix. However, the decrease in apoptosis of Gr-1 + cells may still not account for the entire intrinsic defect. For example, CD18 may regulate apoptosis in rarer, more primitive hematopoietic cells that give rise to the Gr-1 + population, magnifying the effect of $\mathrm{CD} 18$ deficiency on the number of terminally differentiated cells many fold. The studies presented in our paper suggest that CD18 can directly regulate neutrophil production in the $\mathrm{BM}$ at least in part by regulating the survival of neutrophils and their late-stage precursors in the $\mathrm{BM}$, and by regulating the maintenance or proliferation of their more primitive precursors.

The function of CD18 in regulating the development or proliferation of neutrophil progenitors in the BM is not fully understood. CD11a/CD18 (LFA-1) is expressed on mature leukocytes as well as clonogenic myeloid and erythroid progenitors, whereas CD11b/CD18 (Mac-1) is expressed on mature myeloid cells and on murine hematopoietic progenitors. ${ }^{19}$ CD18 is upregulated early and remains high during myeloid differentiation. ${ }^{20,21}$ The increased frequency of LSK cells in the BM of $\mathrm{CD} 18^{-/-}$mice suggests that CD18 may be involved in the maintenance or proliferation of HSC. Work by Wilson $e a^{22}$ suggest that LFA-1 may be important in mediating interactions between HSCs and the stromal cells of the stem cell niche. Intercellular contact between stem cells and the supporting cells of the stem cell niche are required to regulate the stem cell pool. ${ }^{23}$ Thus, disruption of HSC-niche interactions could contribute to the changes in hematopoiesis observed in the absence of CD18. Chronic inflammation due to host defense defects in the absence of CD18 may cause further alterations in the balance between maintenance and proliferation of hematopoietic progenitors. The combined effects of disrupted niche interactions and chronic inflammation may account for the paradoxical increase in the frequency of stem cells accompanied by an increase in the number of more mature precursors and terminally differentiated cells.

The alteration in lineage distribution of $\mathrm{CD} 18^{-/-}$leukocytes in chimeric animals is unlikely to be due to a difference in the number of repopulating cells in $\mathrm{CD} 18^{-/-}$compared to that in WT fetal liver cells, because the frequency of LSK cells was similar in fetal liver cells from WT and mutant donors, and the increase in the proportion of $\mathrm{CD} 18^{-1-} \mathrm{B}$ cells and neutrophils was accompanied by a decrease in the T-cell compartment. An increased number of myeloid progenitors in the fetal liver of $\mathrm{CD} 18^{-/-}$donors is also unlikely to account for the skew in lineage distribution because the chimeric mice were studied at least 10 weeks after transplantation, a time when committed myeloid precursors from the donor fetal liver are unlikely to still be contributing to myelopoiesis. Traver et $a^{11}$ reported that myeloid progeny derived from transplanted granulocyte-monocyte precursors and common myeloid progenitors from donor fetal liver were undetectable 2 and 3 weeks after transplantation, respectively. Papayannopoulou et $a^{24}$ reported slight defects in the homing of CD18 $8^{-/-}$HSC to the BM or their lodgment within the HSC niche. The increased, rather than decreased, number of $\mathrm{CD}_{1} 8^{-/-}$hematopoietic cells in our studies indicates that any defect in BM homing or lodgment of $\mathrm{CD} 18^{-1-}$ HSCs are compensated in the $\mathrm{CD} 18^{-1-}$ mice. These observations suggest that other integrins may be compensating for CD18 in these processes and/or that the defect in homing and lodgment is counterbalanced by the defects in lineage commitment and differentiation. Rather than exerting its major effect on the proximal events of homing and lodgment during BM reconstitution, our data suggest that CD18 regulates lineage distribution of precursors during neutrophil and lymphocyte development.

CD18 may also have a function in the release of mature neutrophils from the BM. By using BrdU to label dividing 
precursors in the BM and tracking BrdU-labeled neutrophils in the BM and circulating blood, we studied the release of neutrophils at steady state in $\mathrm{CD} 18^{-/-}$and chimeric mice. In both $\mathrm{CD} 18^{-/-}$and chimeric mice, the release of $\mathrm{CD} 18^{-/-}$ neutrophils at 12 and $24 \mathrm{~h}$ was proportionately less than that observed in the WT mice. These observations suggest that CD18 may facilitate migration of the most mature neutrophils from the BM parenchyma to the venous sinusoids and/or neutrophil migration into these vessels. Because this release may be delayed rather than accelerated in the absence of $\mathrm{CD} 18$, there seems to be no function for CD18-mediated adhesion in the migration of neutrophils within the sinusoids before their entering the circulating blood stream. Although our data suggest that CD11/CD18 may facilitate neutrophil egress from the marrow of WT mice, this egress can clearly still happen in the absence of CD18. In fact, in chimeric mice, the 2- to 3 -fold increase in the numbers of $\mathrm{CD} 18^{-1-}$ neutrophils in the blood is identical to that in the BM, suggesting that any defect in the time required for egress is completely compensated.

Our results do not exclude a function for CD18 in regulating neutrophil mobilization during inflammation. Burdon et $a l^{25}$ showed that blocking CD18 with a monoclonal antibody enhanced chemokine-induced release of neutrophils in a femoral BM perfusion system, suggesting that CD18 may have differing functions in baseline neutrophil release and chemokine-induced neutrophil mobilization. Adhesion of neutrophils and other hematopoietic cells to stromal cells or to the extracellular matrix within the BM may retain hematopoietic cells within the BM. Conversely, adhesive interactions may be important in allowing neutrophils to crawl through the BM stroma toward the sinusoids, cross the sinusoidal endothelium, and enter the circulation. Blocking CD49d (the $\alpha$ chain of the integrin VLA-4) with a monoclonal antibody or antagonist inhibited neutrophil release from the BM in response to the chemokine MIP- $1 .{ }^{25}$ In more primitive hematopoietic cells, the integrin VLA-4 $(\alpha 4 \beta 1)$ and the cognate receptor for VLA-4, VCAM-1, have been shown to be important in regulating circulating $\mathrm{HSC} / \mathrm{P}$ numbers at baseline and after enforced mobilization from the $\mathrm{BM}^{26}$ Recently, the interaction between VLA- 4 expressed by BM neutrophils and VCAM-1 expressed in the BM stroma was reported to retain maturing neutrophils in the $\mathrm{BM}^{27}$ The interaction between stromal cell-derived factor 1 (SDF-1) and its receptor CXCR4 appears to be a key signal to retain neutrophils in the BM, and disruption of this axis has been implicated in baseline neutrophil release as well as chemokine-induced neutrophil mobilization. ${ }^{27-30}$ A recent report by Petty et $a l^{27}$ showed that neutrophil adhesion by VLA-4 and VCAM-1 is enhanced by SDF-1 treatment, suggesting a link between integrin signaling and the SDF-1/CXCR4 axis. Whether CD18 is involved in modulating signaling through the CXCR4/SDF-1 axis in neutrophils is not clear. Thus, the function of this integrin in regulating neutrophil retention in the BM and mobilization is complex and bear further scru- tiny. The development of new technologies for dynamic tracking of neutrophil release in vivo will be invaluable in addressing the molecular interactions that regulate neutrophil retention and release at steady state and during inflammation.

In summary, these studies indicate that CD18 deficiency causes a decrease in apoptosis of neutrophils and their precursors in the BM, which may contribute to the resulting increase in neutrophil numbers observed in animals that lack CD18. This function of CD18 does not appear to require CD11/CD18 ligation by stromal cells or defined extracellular matrix. CD18 deficiency causes a change in the lineage distribution of hematopoietic cells in the blood and BM, by increasing the proportion of neutrophils relative to other leukocyte lineages. This skewing of hematopoietic lineages in the blood and BM may be due to the defect in apoptosis. However, other mechanisms not addressed in this paper, including altered trafficking of lymphocytes in peripheral tissues, may also contribute. The changes in apoptosis and lineage distribution of $\mathrm{CD} 18^{-/-}$leukocytes persist even in the presence of normal numbers of WT leukocytes in chimeric mice with no obvious signs of infection, suggesting that these effects are not due to host defense defects. These studies show that $\mathrm{CD} 18$ has a direct function in regulating neutrophil production. Thus, the granulocytosis observed in CD18 null mice and patients with LAD I is due to both defects in host defense and BM-intrinsic functions of $\mathrm{CD} 18$ in regulating neutrophil production.

\section{ACKNOWLEDGEMENTS}

We thank McKenzie Koss, Jindrich Soltys, and Jane Reese for expert assistance and helpful discussions. This work was supported by PHS R37HL048160, R01HL052466, and T32HL007415.

\section{DISCLOSURE/CONFLICT OF INTEREST}

The authors have no financial conflicts of interest.

1. Hynes RO. Integrins: bidirectional, allosteric signaling machines. Cell 2002;110:673-687.

2. Harris ES, Mclntyre TM, Prescott SM, et al. The leukocyte integrins. J Biol Chem 2000;275:23409-23412.

3. Scharffetter-Kochanek K, Lu H, Norman K, et al. Spontaneous skin ulceration and defective $\mathrm{T}$ cell function in CD18 null mice. J Exp Med 1998;188:119-131.

4. Horwitz BH, Mizgerd JP, Scott ML, et al. Mechanisms of granulocytosis in the absence of CD18. Blood 2001;97:1578-1583.

5. Forlow SB, Schurr JR, Kolls JK, et al. Increased granulopoiesis through interleukin-17 and granulocyte colony-stimulating factor in leukocyte adhesion molecule-deficient mice. Blood 2001;98:3309-3314.

6. Stark MA, Huo Y, Burcin TL, et al. Phagocytosis of apoptotic neutrophils regulates granulopoiesis via IL-23 and IL-17. Immunity 2005;22:285294.

7. Weinmann P, Scharffetter-Kochanek K, Forlow SB, et al. A role for apoptosis in the control of neutrophil homeostasis in the circulation: insights from CD18-deficient mice. Blood 2003;101:739-746.

8. Doerschuk CM, Mizgerd JP, Kubo $\mathrm{H}$, et al. Adhesion molecules and cellular biomechanical changes in acute lung injury: Giles F. Filley Lecture. Chest 1999;116(1 Suppl):37S-43S.

9. Nathan C. Points of control in inflammation. Nature 2002;420:846-852.

10. Robker RL, Collins RG, Beaudet $A L$, et al. Leukocyte migration in adipose tissue of mice null for ICAM-1 and Mac-1 adhesion receptors. Obes Res 2004;12:936-940. 
11. Traver D, Miyamoto T, Christensen J, et al. Fetal liver myelopoiesis occurs through distinct, prospectively isolatable progenitor subsets. Blood 2001;98:627-635.

12. Basu S, Hodgson G, Katz M, et al. Evaluation of role of G-CSF in the production, survival, and release of neutrophils from bone marrow into circulation. Blood 2002;100:854-861.

13. Bicknell $S$, van Eeden $S$, Hayashi $S$, et al. A non-radioisotopic method for tracing neutrophils in vivo using $5^{\prime}$-bromo-2'-deoxyuridine. Am J Respir Cell Mol Biol 1994;10:16-23.

14. Shih $\mathrm{CH}$, Whalen BA, Goto Y, et al. Flow cytometric method for enumeration and characterization of newly released polymorphonuclear leukocytes from the bone marrow using $5^{\prime}$ bromo-2'-deoxyuridine. Am J Physiol Cell Physiol 2005;289:C757-C765

15. Fleming TJ, Fleming ML, Malek TR. Selective expression of Ly-6G on myeloid lineage cells in mouse bone marrow. RB6-8C5 mAb to granulocyte-differentiation antigen (Gr-1) detects members of the Ly-6 family. J Immunol 1993;151:2399-2408.

16. Hestdal K, Ruscetti FW, Ihle JN, et al. Characterization and regulation of RB6-8C5 antigen expression on murine bone marrow cells. J Immunol 1991;147:22-28.

17. Smith E, Zarbock A, Stark MA, et al. IL-23 is required for neutrophil homeostasis in normal and neutrophilic mice. J Immunol 2007; 179:8274-8279.

18. Mayadas TN, Cullere X. Neutrophil beta2 integrins: moderators of life or death decisions. Trends Immunol 2005;26:388-395.

19. Chan JY, Watt SM. Adhesion receptors on haematopoietic progenitor cells. Br J Haematol 2001;112:541-557.

20. Lian Z, Kluger Y, Greenbaum DS, et al. Genomic and proteomic analysis of the myeloid differentiation program: global analysis of gene expression during induced differentiation in the MPRO cell line. Blood 2002;100:3209-3220.

21. Lian Z, Wang L, Yamaga S, et al. Genomic and proteomic analysis of the myeloid differentiation program. Blood 2001;98:513-524.

22. Wilson A, Murphy MJ, Oskarsson T, et al. c-Myc controls the balance between hematopoietic stem cell self-renewal and differentiation. Genes Dev 2004;18:2747-2763.

23. Wilson A, Trumpp A. Bone-marrow haematopoietic-stem-cell niches. Nat Rev Immunol 2006;6:93-106.

24. Papayannopoulou T, Priestley GV, Nakamoto B, et al. Molecular pathways in bone marrow homing: dominant role of alpha(4)beta(1) over beta(2)-integrins and selectins. Blood 2001;98:2403-2411.

25. Burdon PC, Martin C, Rankin SM. The CXC chemokine MIP-2 stimulates neutrophil mobilization from the rat bone marrow in a CD49ddependent manner. Blood 2005;105:2543-2548.

26. Papayannopoulou T. Current mechanistic scenarios in hematopoietic stem/progenitor cell mobilization. Blood 2004;103:1580-1585.

27. Petty JM, Lenox CC, Weiss DJ, et al. Crosstalk between CXCR4/stromal derived factor-1 and VLA-4/VCAM-1 pathways regulates neutrophil retention in the bone marrow. J Immunol 2009;182:604-612.

28. Martin C, Burdon PC, Bridger G, et al. Chemokines acting via CXCR2 and CXCR4 control the release of neutrophils from the bone marrow and their return following senescence. Immunity 2003;19:583-593.

29. Suratt BT, Petty JM, Young SK, et al. Role of the CXCR4/SDF-1 chemokine axis in circulating neutrophil homeostasis. Blood 2004;104:565-571.

30. Wengner AM, Pitchford SC, Furze RC, et al. The coordinated action of G-CSF and ELR + CXC chemokines in neutrophil mobilization during acute inflammation. Blood 2008;111:42-49. 